\title{
A test of two methods for extinguishing Pavlovian conditioned inhibition
}

\author{
ELIZABETH S. WITCHER and JOHN J. B. AYRES \\ University of Massachusetts, Amherst, Massachusetts
}

\begin{abstract}
Two experiments were performed using rats in a conditioned suppression procedure to test two different methods for extinguishing Pavlovian conditioned inhibition. In both experiments, a target stimulus, $\mathrm{X}$, was made inhibitory by giving discrimination training of the form $\mathrm{A}+$ AX-. Then, in Experiment 1, an attempt was made to extinguish the inhibition conditioned to $\mathrm{X}$ by presenting nonreinforced occurrences of $\mathrm{X}$, of $\mathbf{A X}$, and of $\mathbf{A}$. Testing for conditioned inhibition took the form B+ BX-. It was found that the extinction procedure did not weaken the inhibitory properties of $X$. Experiment 2 attempted to extinguish the inhibition conditioned to $\mathrm{X}$ by presenting $\mathrm{X}$ randomly and independently of the reinforcer, electric grid shock. This procedure appeared to weaken inhibition quickly and permanently.
\end{abstract}

Zimmer-Hart and Rescorla (1974) reported that Pavlov's extinction procedure of presenting conditioned stimuli (CSs) without unconditioned stimuli (USs) was ineffective in extinguishing conditioned inhibition. The only method they found to be effective was one that involved pairing the inhibitory CS with the US. The present research was designed to investigate further the extinction of conditioned inhibition. Two experiments are reported. In both, a target stimulus, $\mathrm{X}$, was established as a conditioned inhibitor by intermingling reinforced occurrences of a second stimulus, $A$, with nonreinforced occurrences of $A$ and $X$ in combination. In this paradigm ( $A+A X-)$, stimulus $A$ acquires the ability to excite a conditioned response, and stimulus $X$ acquires the ability to oppose that excitation. Following training of this sort, an attempt was made to extinguish the inhibition conditioned to stimulus X. Experiment 1 used a method of presenting CSs without USs similar to the method of Zimmer-Hart and Rescorla but modified somewhat in an effort to promote extinction. Experiment 2 used a truly random control procedure, a procedure advocated by Rescorla (1967) as an appropriate one for extinguishing both conditioned excitation and conditioned inhibition. With this method, the target CS is presented randomly and independently of the US. This procedure was expected by Rescorla to degrade whatever predictive relationship existed previously

This paper is based upon a doctoral dissertation submitted by E. S. Witcher to the Graduate School of the University of Massachusetts, Amherst, in 1978, in partial fulfillment of the requirements for the $\mathrm{PhD}$ degree. The research was supported in part by Grant MH 28226-01 from the National Institute of Mental Health. The authors wish to thank Daniel R. Anderson, John W. Moore, Melinda A. Novak, and Theodore D. Sargent who served as members of the dissertation committee, and Michael Vigorito for his criticisms of a recent draft of the manuscript. Requests for reprints should be addressed to John J. B. Ayres, Department of Psychology, Middlesex House, University of Massachusetts, Amherst, MA 01003. between the CS and the US, and thus to reduce the CS's conditioned strength, be it excitatory or inhibitory.

Like the earlier work of Zimmer-Hart and Rescorla (1974), both of the present experiments used the conditioned suppression procedure with rat subjects. In this procedure, a CS's excitatory strength is indexed in terms of its ability to disrupt ongoing operant behavior.

\section{EXPERIMENT 1}

Experiment 1 was similar in intent to the Experiment 1 described by Zimmer-Hart and Rescorla (1974). In that study, rats were first given $\mathrm{A}+\mathrm{B}+\mathrm{AX}$ - training to establish $A$ and $B$ as conditioned excitors and $X$ as a conditioned inhibitor; then, for an experimental group, an attempt was made to extinguish the inhibitory properties of $\mathrm{X}$ by repeatedly presenting it nonreinforced. Control subjects at this time received only exposure to the conditioning apparatus. Then both groups were tested by the presentation of $\mathbf{A}$ or $\mathbf{B}$ on some occasions and of $\mathrm{AX}$ or $\mathrm{BX}$ on other occasions. Stimuli A and B were expected to produce conditioned suppression, and $X$ was expected to alleviate that suppression when compounded with either $A$ or $B$. This ability of $X$ to alleviate suppression to $A$ and $B$ was expected to be weaker in the experimental group to the extent that the prior presentations of $X$ alone had reduced its inhibitory strength. However, Zimmer-Hart and Rescorla found that $\mathbf{X}$ alleviated suppression to $\mathbf{A}$ and $B$ equally in both groups.

It seemed possible to us that two factors might have worked against the effectiveness of the CS-alone extinction procedure that Zimmer-Hart and Rescorla used. First, when $\mathrm{X}$ was nonreinforced during the CS-alone extinction phase, it was nonreinforced in a context (the ever-present apparatus cues) possibly made excitatory by being reinforced in compound with stimuli $\mathbf{A}$ and $B$ in the preceding phase. Nonreinforcement of a stimulus in an excitatory context is thought to be 
sufficient to establish conditioned inhibition, not to extinguish it (Rescorla \& Wagner, 1972). Second, the establishment of X's inhibitory strength presumably depended on the prior acquisition of excitation by stimulus A. It seemed possible, therefore, that excitation to $A$ and inhibition to $X$ could somehow be interdependent. If so, then it might be necessary to eliminate A's excitatory strength before X's inhibitory strength could be extinguished (cf. Rescorla, 1982). If this were done, then it might subsequently be prudent to avoid using an excitatory A stimulus in the final test of X's inhibitory strength; if excitation to $A$ and inhibition to $\mathrm{X}$ were truly interdependent, then reestablishing excitation to $\mathrm{A}$ might inadvertently restore inhibition to $\mathrm{X}$.

In the present study, rats were first given $\mathbf{A}+\mathbf{A X}$ training to establish $A$ as an excitor and $X$ as an inhibitor. Next, while control subjects were exposed to only the conditioning apparatus, an attempt was made to extinguish inhibition to $X$ in experimental animals by presenting repeated nonreinforced occurrences of $\mathbf{X}$, of $\mathrm{AX}$, and of $\mathbf{A}$. This procedure was continued until subjects no longer showed suppression to A. The reasoning was that if $\mathbf{A}$ were no longer excitatory, then the background apparatus cues, previously reinforced in compound with A on A+ trials, would no longer be excitatory either. This would reduce the likelihood that the "extinction" procedure actually entailed nonreinforced presentations of stimulus $X$ in an excitatory context.

In the test stage that followed, both the experimental group and the control group were subjected to a B+ BXprocedure. It was expected that $\mathrm{X}$ would come to alleviate suppression to $B$ more readily in the control group than in the experimental group for which X's inhibitory properties had just been weakened (presumably) by the prior nonreinforced presentations of $\mathrm{X}, \mathrm{A}$, and $\mathrm{AX}$. Notice that stimulus $\mathbf{A}$ was not used at all in the final test and that its excitatory strength was not reestablished prior to testing. ${ }^{1}$

\section{Method}

\section{Subjects}

Sixteen Holtzman male albino rats, 95-105 days old at the start of the experiment, were housed individually in suspended wire-mesh cages located in a continuously lighted room and were maintained on a 22-h water-deprivation schedule; Purina Lab Chow was freely available.

\section{Apparatus}

Eight Gebrands operant chambers were housed in ventilated $.61-\mathrm{m}$ cubes of $12.7-\mathrm{mm}$ plywood lined with acoustical tile. The inside dimensions of each chamber were $23.2 \times 20.3 \times 19.5 \mathrm{~cm}$. Each floor was composed of 18 stainless steel rods, $2 \mathrm{~mm}$ in diameter, mounted $1.3 \mathrm{~cm}$ apart center to center. The end walls were aluminum, and the side walls and top were transparent Plexiglas. Centered in one end wall was a standard Gerbrands bar, $1.5 \times 5.0 \mathrm{~cm}$, mounted $8 \mathrm{~cm}$ above the grid floor. In the lower left corner of this same wall was a $5.5 \times 5.0 \times 5.0 \mathrm{~cm}$ recessed dipper receptacle, which allowed the presentation of liquid reinforcement in a .1-ml dipper cup.

On the lid of each operant chamber were two $10-\mathrm{cm}$ speakers. One presented a $1000-\mathrm{Hz} 84-\mathrm{dB}$ tone (re $20 \mu \mathrm{N} / \mathrm{m}^{2}$ ), hereafter referred to as stimulus $A$; the other presented an $87-\mathrm{dB}$ white noise (re $20 \mu \mathrm{N} / \mathrm{m}^{2}$ ), hereafter referred to as stimulus B. A $28-\mathrm{V}$ cue lamp mounted over the dipper opening $95 \mathrm{~mm}$ above the grid floor and a second $28-\mathrm{V}$ bulb mounted on the chamber lid provided a third CS, hereafter referred to as stimulus $X$. This stimulus was created by changing the voltage across the two bulbs together once per second from 6.5 to $26 \mathrm{~V}$. The USs used were scrambled electric grid shocks, $.5 \mathrm{sec}$ in duration and $.8 \mathrm{~mA}$ in intensity; these were produced by eight Grason-Stadler shock generators (Models E1064GS and 700).

\section{Procedure}

Preliminary training. Rats were water deprived for $48 \mathrm{~h}$; then in one session, lasting up to $2 \mathrm{~h}$, they were shaped to barpress for water. Criterion was met when the rats made 50 responses in this period. At the end of this first session and each following session, the rats were given access to water in their home cages for $5 \mathrm{~min}$ only. Five daily 2 -h sessions followed with a VI 1-min schedule of water reinforcement in effect.

Conditioned inhibition training. This phase was designed to establish a tone CS (A) as a conditioned excitor and a flashing light $\mathrm{CS}(\mathrm{X})$ as a conditioned inhibitor. All rats were given six reinforced presentations of $A$ and six nonreinforced presentations of $X$ presented in simultaneous compound with $A$. The $A$ and AX stimuli were presented randomly in time with the requirement that they not overlap and that each block of two trials contain one $A$ and one $A X$ presentation. All CSs were $2 \mathrm{~min}$ long; the US was a .5 -sec . 8 -mA shock, and it began with the termination of stimulus $A$. This treatment continued for a total of 11 days.

Throughout conditioned inhibition training, the rats continued to barpress and receive water on the VI schedule. Response rates were monitored throughout. The effects of stimulus presentations were assessed in terms of the amount of suppression during the stimulus. Suppression was measured by forming a ratio of response rates of the form $D /(D+B)$, where $D$ is the number of responses during a $C S$ and $B$ is the number in an equal period immediately preceding the CS (Annau \& Kamin, 1961). With this ratio, a score of 0 indicates complete suppression to the CS (i.e., excitatory conditioning), and a ratio of .5 suggests that the CS has no effect on responding.

CS-alone extinction procedure. For the next 6 days, half the rats, those in Group C (a forgetting control), continued to barpress for water on a VI 1-min schedule. The remaining rats, those in Group $\mathrm{E}$ (the experimental group), received in each 2 -h session four nonreinforced presentations each of the $A, A X$, and $X$ stimuli superimposed on barpressing in a random order.

Test for conditioned inhibition. In this phase, both groups received $\mathrm{B}+\mathbf{B X}-$ discrimination training similar to their original $A+A X-$ discrimination training, except that a white-noise CS (stimulus B) was substituted for the A stimulus of earlier training. In four daily 2-h sessions, each rat received six reinforced presentations of an 87-dB white noise (B) and six nonreinforced presentations of the flashing light $(X)$ in simultaneous compound with $B(B X)$. All stimuli again were $2 \mathrm{~min}$ in duration, and the US was a $.5-\sec .8-\mathrm{mA}$ shock.

\section{Results}

The results of Experiment 1 are presented in Figure 1 in terms of the group mean suppression ratios associated with: (1) reinforced $A$ and nonreinforced $A X$ trials during initial discrimination training for Groups $E$ and $C$ (Panel A); (2) nonreinforced $\mathrm{A}, \mathrm{AX}$, and $\mathrm{X}$ trials during the CS-alone extinction phase for Group E (Panel B); and (3) reinforced $B$ and nonreinforced $B X$ trials during the test for conditioned inhibition in both Groups $\mathrm{E}$ and C (Panel C). 


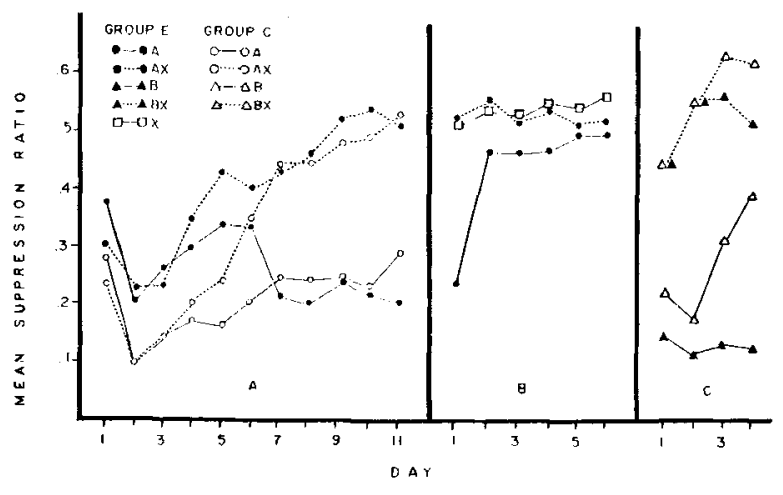

Figure 1. Mean suppression ratios for Groups $E$ and $C$ in Experiment 1. Panel A: Discrimination training. Panel B: CSalone extinction (Group E only). Panel C: Final test for inhibition.

During initial discrimination training (Panel A), Groups $\mathrm{E}$ and $\mathrm{C}$ learned to discriminate between $\mathrm{A}$ and AX at similar rates. At the end of training, rats in both groups suppressed during (reinforced) A presentations and did not suppress during (nonreinforced) AX presentations. There were no significant differences between the two groups during this phase $(t<1)$.

During the CS-alone extinction phase (Panel B), nonreinforced $\mathrm{AX}$ trials continued to have no apparent effect on barpressing, but A trials rapidly lost their ability to suppress responding. Presentations of $X$ also had little effect upon responding. By the end of extinction, there were no significant differences in the effects of the three stimuli $[\operatorname{ts}(7)<2.05$, ps $>.05] .^{2}$

During the test for conditioned inhibition (Panel C), no significant differences between Groups $\mathrm{E}$ and $\mathrm{C}$ were found. Indeed, both groups showed a strong differentiation between $B$ and $B X$ trials on the 1st day of testing. Because transfer was so immediate, efforts to find differences between the two groups were concentrated on the early trials of Day 1 of testing. However, inspection of the group mean suppression ratios on the 12 stimulus trials on Day 1 in the order in which the stimuli were presented (data not shown) did not reveal any obvious group differences. Both groups responded similarly on the first BX and B presentations; by the second time the $B X$ and $B$ cues were presented, $B$ suppressed responding while $X$ attentuated suppression when compounded with B. This trend of increasing suppression to $B$, accompanied by increased attentuation of suppression on BX trials, continued in a similar fashion for both groups on Day 1, although Group C appeared to develop somewhat weaker suppression to B than did Group E. Analysis of difference scores (i.e., suppression ratios during $B$ minus suppression ratios during BX) for the 1 st day of testing and for the 4 days of testing overall revealed no significant group differences $[\operatorname{ts}(14)<1.67$, ps $>.10]$.

The left portion of Table 1 shows the group mean pre-CS responding (responses/2-min pre-CS period) for the last day of discrimination training, the last day of extinction, and the 1st day of summation testing. These data were analyzed using mixed design (groups $X$ stimulus type) analyses of variance for discrimination and test data and by a repeated measures (stimulus type) analysis of variance for the extinction data. Because of the number of tests conducted, the rejection level was set at .01 to avoid inflating the Type I error rate. These analyses showed no differences among groups or stimulus types and no significant interactions. An a priori analysis was then conducted to determine whether pre-CS responding was greater at the end of extinction than at the end of discrimination training for Group E. Nonreinforced exposure to previously conditioned contextual cues during extinction might have been expected to produce such an increase. Accordingly, a correlated $t$ test found that the mean pre-CS responding (averaged over all three stimulus types) on the last day of extinction was indeed greater than the mean pre-CS responding (averaged over both stimulus types) on the last day of discrimination training $[t(7)=2.74, p<.05]$.

\section{Discussion}

The main finding of this study is that the nonreinforced presentations of $\mathbf{A}, \mathbf{A X}$, and $\mathbf{X}$ trials following $A+A X$ - discrimnation training failed to extinguish the inhibitory properties of $\mathrm{X}$. Following CS-alone extinction training, Group E acquired a B+ BX-discrimination equally as fast as did Group $C$. This result supports the findings of Zimmer-Hart and Rescorla (1974), and suggests that excitatory background cues and an excitatory stimulus $A$ in their study were not responsible for the ineffectiveness of their CS-alone extinction procedure (cf. Rescorla, 1982).

Table 1

Mean Pre-CS Responding

\begin{tabular}{|c|c|c|c|c|c|c|c|c|c|c|c|c|c|c|c|}
\hline \multirow[b]{2}{*}{ Group } & \multicolumn{7}{|c|}{ Stimulus } & \multicolumn{8}{|c|}{ Stimulus } \\
\hline & $\mathbf{A}$ & $\mathbf{A X}$ & A & $\mathbf{A X}$ & $\mathrm{X}$ & B & BX & Group & $\mathbf{A}$ & $A X$ & AY & ALL & $\mathbf{A}$ & $\mathbf{A X}$ & $\mathbf{A Y}$ \\
\hline $\begin{array}{l}\mathrm{E} \\
\mathrm{C}\end{array}$ & $\begin{array}{l}12 \\
18 \\
\end{array}$ & $\begin{array}{l}12 \\
17 \\
\end{array}$ & 21 & 27 & 21 & $\begin{array}{l}18 \\
13 \\
\end{array}$ & $\begin{array}{l}18 \\
13\end{array}$ & $\begin{array}{l}\mathbf{E} \\
\mathbf{N}\end{array}$ & 12 & 14 & 13 & $\begin{array}{l}7 \\
6\end{array}$ & $\begin{array}{r}9 \\
10\end{array}$ & $\begin{array}{l}10 \\
12\end{array}$ & $\begin{array}{r}8 \\
13\end{array}$ \\
\hline
\end{tabular}

Note-The pre-CS period was 2 min in Experiment 1 and 1 min in Experiment 2. *Data not available. 


\section{EXPERIMENT 2}

When Rescorla (1967) first described the truly random control procedure and offered it as the appropriate control for use in Pavlovian conditioning experiments, he also advocated it as "an unbiased procedure for extinction of both excitation and inhibition" (Rescorla, 1967 , p. 75 , italics in the original). Since Zimmer-Hart and Rescorla (1974) did not test such a procedure in their work on the extinction of conditioned inhibition, we decided to test it here.

The general strategy adopted in this experiment was as follows. First, one group of rats, Group E, was given A+ AX- AY- discrimination training designed to establish stimulus $A$ as a conditioned excitor and stimuli $X$ and $\mathrm{Y}$ as conditioned inhibitors. Next, an attempt was made to extinguish the inhibitory properties of one of the two inhibitors $(\mathrm{X})$ by presenting it randomly and independently of shock USs. During this training, which was given while the rats barpressed, A+ trials continued to be presented so as to maintain A's excitatory strength. In addition, occasional $\mathbf{A X}$ or $\mathbf{A Y}$ probe trials were given so that any changes in the inhibitory characteristics of $\mathrm{X}$ and $\mathrm{Y}$ might be monitored during the truly random "extinction" treatment. After this phase came a test consisting of presentations of $\mathbf{A}, \mathbf{A X}$, and $\mathrm{AY}$, all nonreinforced. The question of interest was whether $Y$ would have a greater ability to attenuate suppression to A than would $X$. In addition, a second group of rats was included to provide information about how the truly random "extinction" procedure would affect stimulus $X$ if $X$ had begun that training as a novel stimulus rather than as a previously established conditioned inhibitor.

\section{Method}

\section{Subjects and Apparatus}

The subjects were 16 male albino rats similar to those of Experiment 1. They were maintained at $80 \%$ of their freefeeding body weights throughout experimentation and were housed as before. The apparatus was unchanged.

\section{Procedure}

Preliminary training. In a single $1-h$ magazine training session, the bars were removed from the operant chambers, and 4-sec presentations of $32 \%$ (by weight) sucrose were presented at variable times averaging $1 \mathrm{~min}$. On the next day, the bars were replaced and a 4 -sec presentation of $32 \%$ sucrose was made contingent on each barpress until 50 barpresses had occurred. If necessary, the rats were hand-shaped to barpress. Five daily 2-h sessions followed with a VI 2-min schedule of reinforcement in effect. In the initial session, however, sucrose was delivered on a VI 1-min schedule for the first $20 \mathrm{~min}$.

Discrimination training. Discrimination training was given to one group of eight rats (Group E) and took the form At AX-AY-. It was designed to establish stimulus $A$ as a conditioned excitor and stimuli $X$ and $Y$ as conditioned inhibitors. Stimulus A was a $75-\mathrm{dB}\left(\mathrm{re} \mu \mathrm{N} / \mathrm{m}^{2}\right)$ white noise; and the other two stimuli were a flashing light, as in Experiment 1 , and an intermittent $(1 / \mathrm{sec}) 1000-\mathrm{Hz} 84-\mathrm{dB}$ tone.

During the first two 2-h sessions of discrimination training, each rat received four reinforced presentations of stimulus $A$. During each of the following sessions, each rat received four reinforced A trials and four nonreinforced presentations of each of the compound stimuli (AX and AY). All stimuli were $1 \mathrm{~min}$ in duration; reinforcement was a 1-sec 1-mA shock. Training with the three stimuli ( $\mathrm{A}, \mathbf{A X}$, and $\mathrm{AY}$ presented in a random order) continued for 41 days.

A second group of eight rats (Group N) received during the discrimination training phase the same A+ trials as did Group E, but experienced no compound trials (AX or AY).

Truly random extinction. At the start of this stage of the experiment, one rat in Group $\mathbf{E}$ was dropped from the study for failing to form the discriminations required in the previous phase. The remaining seven rats in that group received a procedure in which stimulus $X$ was presented randomly and independently of shock USs in an effort to extinguish X's inhibitory strength. For four of the seven rats in Group E, stimulus X was the flashing light (Subgroup E-L), and for the other three rats, stimulus $\mathrm{X}$ was the intermittent tone (Subgroup E-T).

On each day of truly random extinction, the rats in Subgroups E-L and E-T received two reinforced white-noise trials (A) designed to maintain $\mathrm{A}$ as an excitor. In addition, the rats received $24 \mathrm{X}$ trials and $101-\mathrm{sec} 1-\mathrm{mA}$ shock USs presented randomly and independently of each other. The random schedule of CSs (X) and USs was computer generated, with the restriction that the number of pairings of CS and US occurring per session had to be equal to the number of CS-US pairings expected by chance (i.e., two) and that trials of different types would not overlap. ${ }^{3}$ This training continued for 8 days while the rats continued to barpress for sucrose on the VI 2-min schedule. On the odd-numbered days of truly random training, a single nonreinforced AY probe trial was superimposed on responding, and on even days, a single AX probe trial was superimposed on responding in order to monitor any changes that might occur in the degree of conditioned inhibition controlled by $X$ and $Y$.

Group $N$, during this phase, received the same procedure as did Group E. Four rats experienced light as the $X$ stimulus (Subgroup N-L), and four rats experienced tone (Subgroup N-T).

Recovery. In four 2-h sessions, all rats were allowed to barpress for sucrose on the VI 2-min schedule without presentation of CSs or shock USs. The intent of this procedure was to ensure a nonexcitatory background against which to test the effects of interest.

Test for conditioned inhibition. In this phase, both groups received in a single $2-h$ session two $A$, two $A X$, and two $A Y$ trials, all nonreinforced in a random order. If stimulus $X$ had lost inhibitory strength during the preceding phase for Group $E$, then it should be less effective than stimulus $Y$ at attenuating suppression to $\mathrm{A}$.

\section{Results}

\section{Group E}

The results of discrimination training for Group $E$ are presented in Figure 2. Panel A shows preliminary At conditioning results. Suppression to A was rapidly acquired in Group E. Panel B shows the results of discrimination training per se. Data are plotted in 3-day blocks. Since dividing 41 days into 3 -day blocks yields 2 days left over, we arbitrarily omitted the first 2 days from the figure. It is clear from Figure 2 that discriminations between the noise and the compounds of noise + light and noise + tone were formed gradually. The discrimination between noise and noise + light was formed more rapidly than that between noise and noise + tone; and, on the last day of training, rats in Group E sup- 


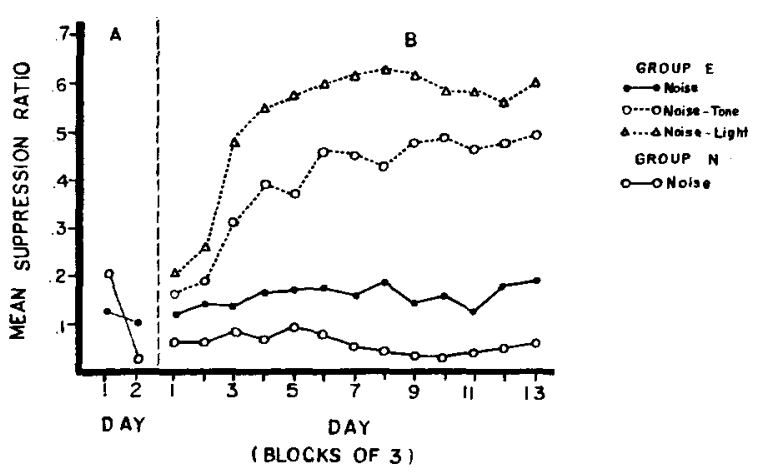

Figure 2. Mean suppression ratios for Groups $E$ and $N$ in Experiment 2. Panel A: Preliminary At training. Panel B: Discrimination training for Group $E$, continued $A+$ training for Group N.

pressed significantly less during noise + light trials than during noise + tone trials $[\mathrm{t}(6)=3.06, \mathrm{p}<.05]$.

Data representing the mean effects of $A, X$, and (alternating) AX and AY stimuli on each day of truly random training for Subgroups E-L and E-T are presented in Figure 3 (Panels $A$ and $C$, respectively). For Subgroup E-L, $\mathrm{X}$ was the light and $\mathrm{Y}$ the tone, whereas for Subgroup E-T the opposite was true. Each data point for $A$ is based on 2 trials, each point for $X$, on 24 trials, and each point for $\mathrm{AX}$ and $\mathrm{AY}$, on only 1 trial. During the truly random treatment, suppression ratios of the form $D /(D+B)$ were computed as usual; however, $D$ represented the response rate per minute during a $\mathrm{CS}$, and $B$ represented the rate averaged over all non-CS portions of the sessions.

The data for Subgroups E-L and E-T are similar. For the most part, rats suppressed to $A$ throughout training. They did not suppress on $X$ trials, and, in general, did not suppress on AY probe trials. However, a comparison of suppression to $\mathbf{A X}$ on the last day of discrimination training with that on the first $\mathrm{AX}$ probe revealed that the truly random training quickly produced a significant increase in suppression to $A X[t(6)=$ $4.69, \mathrm{p}<.01$ ] . A similar comparison of suppression to AY revealed no significant change $[t(6)=1.53, p>.10]$. Both comparisons are based on data pooled across subgroups. The suppression to $\mathbf{A X}$ early in truly random training weakened during training, and rats in both subgroups suppressed less on the last $\mathrm{AX}$ probe than on the first [pooled data, $t(5)=9.45, p<.001] .^{4}$

The results of the final test for conditioned inhibition, given after the recovery sessions that followed truly random training, are shown for Subgroups E-L and E-T in Figure 3, Panels B and D, respectively. The data of both subgroups are similar in form, although absolute suppression levels differ between groups. Although rats in both subgroups suppressed on $A$ and AX trials, they did not suppress during AY presentations, irrespective of the modality of the $X$ and $Y$ stimuli (i.e., whether they were light or tone). A comparison (based on pooled data) of difference scores (i.e., the difference between suppression ratios on $\mathbf{A}$ and $\mathrm{AX}$ trials on the last day of discrimination training and during testing) revealed a statistically significant decrease in the ability of $\mathrm{X}$ to attenuate suppression to A following truly random training $[\mathrm{t}(6)=4.59, \mathrm{p}<.01]$. A similar (pooled) comparison of difference scores for suppression ratios on $A$ and $A Y$ trials revealed no significant change in the ability of $Y$ to attenuate suppression to $A(t<1)$.

\section{Group N}

Data for Group $\mathbf{N}$ during preliminary $\mathrm{A}+$ training and continued At training are presented in Figure 2, Panels A and B, respectively. Suppression to A (the noise) was rapidly acquired and remained strong over 41 days of training. It might be noted that Group $N$ suppressed consistently more to $\mathbf{A}$ than did Group $\mathbf{E}$ during this phase of the experiment. This difference may be due to the fact that Group $\mathrm{N}$ never experienced nonreinforced trials.

Suppression to $\mathbf{A}, \mathbf{X}, \mathbf{A X}$, and $\mathrm{AY}$ during truly random training for Subgroups N-L and N-T is depicted in Figure 4, Panels $\mathrm{A}$ and $\mathrm{C}$, respectively. Both subgroups continued to suppress to A throughout training; neither suppressed to $X$, and for both, suppression to $A X$ was similar to suppression to $A$ alone. Although rats in

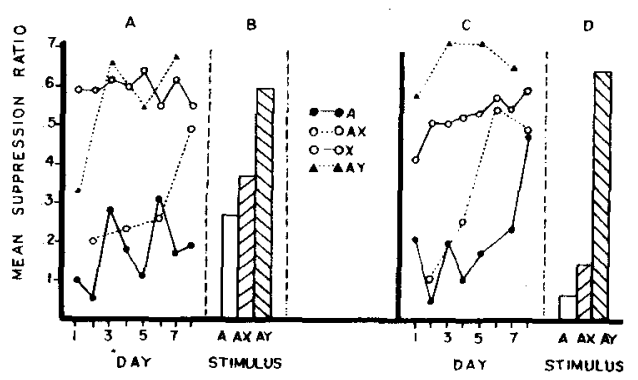

Figure 3. Mean suppression ratios for Subgroups E-L and E-T in Experiment 2. Panel A: Truly random "extinction" for Subgroup E-L. Panel B: Final test for conditioned inhibition for Subgroup E-L. Panel C: Truly random extinction for Subgroup E-T. Panel D: Final test for conditioned inhibition for Subgroup E-T.

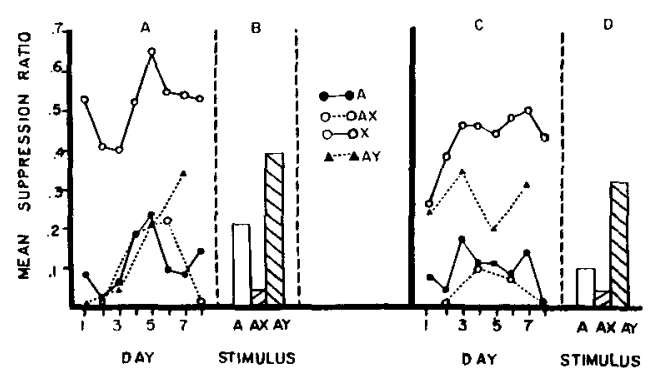

Figure 4. Mean suppression ratios for Subgroups N-L and N-T in Experiment 2. Panel A: Truly random "extinction" for Subgroup N-L. Panel B: Final test for conditioned inhibition for Subgroup N-L. Panel C: Truly random "extinction" for Subgroup N-T. Panel D: Final test for conditioned inhibition for Subgroup E-T. 
Subgroup N-T (Panel C) suppressed somewhat less on AY trials than on A trials, this difference for the two subgroups combined was not significant $[\mathrm{t}(7)=1.61$, $\mathrm{p}>.10]$.

Final test results for Subgroups N-L and N-T are presented in Figure 4, Panels B and D, respectively. The rats suppressed significantly more on $A X$ trials than on AY trials regardless of the modality of the $X$ and $Y$ stimuli [pooled data $t(7)=3.85, p<.01]$. Notice that $\mathrm{X}$ tended to enhance suppression to $\mathrm{A}$ somewhat in both subgroups, and $\mathrm{Y}$ tended to reduce it. These effects were not statistically significant.

The right portion of Table 1 shows the mean pre-CS responding (responses/1-min pre-CS period) for the last day of discrimination training, for all 8 days of "extinction," and for the single summation test day. During extinction, the random nature of stimulus presentations precluded the use of fixed pre-CS periods. The response rate per minute in the absence of programmed stimuli was therefore used as the estimate of the pre-CS rate for all stimulus types presented in extinction. Analyses of response rates similar to those described for Experiment 1 once again found no significant effects of groups, stimulus types, or their interaction. An a priori analysis was then conducted to determine whether pre-CS responding decreased during extinction relative to the last day of discrimination training in Group E. Such a decrease might have been expected since during truly random extinction most USs were not paired with any CSs but only with contextual cues. Although each of the seven rats responded more slowly in extinction than on the last day of discrimination training, as anticipated, the change was not statistically significant according to a correlated $t$ test $[\mathrm{t}(6)=2.27 ; 2.45$ required at the .05 level].

\section{Discussion}

The main finding of Experiment 2 was that the truly random procedure was successful in weakening the inhibitory power of $X$. Moreover, the effects of the truly random "extinction" procedure were specific to the one inhibitory stimulus (X) that was experienced in a truly random fashion with respect to shock; the ability of a second inhibitory stimulus (Y) to attenuate excitation was not diminished. In contrast to data that indicate that truly random treatments are slow to reduce previously established excitatory tendencies (Ayres \& DeCosta, 1971; Keller, Ayres, \& Mahoney, 1977), the effects of the truly random treatment on X's inhibitory power were almost immediate (according to the AX probe data) and certainly robust (according to the final test).

Why did truly random training weaken the inhibitory strength of stimulus $X$ ? One plausible interpretation is based on the following considerations: First, a considerable body of evidence indicates that truly random training may produce excitatory conditioning (Ayres,
'Benedict, \& Witcher, 1975; Benedict \& Ayres, 1972; Keller et al., 1977; Kremer, 1971, 1974; Kremer \& Kamin, 1971; Quinsey, 1971; Witcher \& Ayres, 1975). Second, there is evidence that this conditioning is due to chance CS-US pairings that occur early in the truly random sequence of events (Ayres et al., 1975; Benedict \& Ayres, 1972). Third, the excitatory conditioning produced by these early chance pairings weakens with extended truly random training (Keller et al., 1977).

The results of the present experiment were entirely consistent with the possibility that early chance pairings of $X$ and the US in the truly random control made $X$ mildly excitatory initially, but that with continued truly random training this excitation weakened, leaving $X$ approximately neutral, not excitatory in Group E, but certainly less inhibitory than $\mathrm{X}$ once had been.

The results consistent with the above description were as follows. First, for Group E, suppression on the first $\mathrm{AX}$ probe trial during truly random training was stronger than it had been on the last day of discrimination training. This is consistent with the possibility that early chance pairings during truly random training conditioned mild excitation to $X$. A similar increase in suppression on the first AY probe trial did not occur, presumably because $Y$ was never chance-paired with shock. Second, suppression on succeeding $\mathbf{A X}$ probe trials for Group E weakened over the course of truly random training. This is consistent with the observation (Keller et al., 1977) that the excitatory conditioning produced by early chance CS-US pairings in the truly random control weakens with extended training. Third, for Group $\mathrm{N}$, there was significantly more suppression on AX trials in the final test than on AY trials. This result is again consistent with the idea that $X$ became mildly excitatory as a result of chance X-US pairings during truly random training, provided we assume that the relatively novel stimulus, $\mathrm{Y}$, was associatively neutral. On the other hand, it is also consistent with the idea that $X$ was left associatively neutral by the truly random procedure while $Y$ became mildly inhibitory. If so, then $Y$ would have had to become inhibitory as a result of only four unreinforced AY probe trials. Given the extreme slowness with which conditioned inhibition apparently develops (see, e.g., Figure 2) and given the known rapidity with which excitatory conditioning can be produced by the early chance pairings in the truly random control (Ayres et al., 1975), the first of these two possibilities seems more likely.

If the interpretation is that $\mathrm{X}$ became mildly excita. tory as a result of early chance X-US pairings during truly random training, then one might reasonably expect $X$ to control conditioned suppression during truly random training. Inspection of Figures 3 and 4 does not, however, reveal much suppression to $\mathrm{X}$, especially in Group E. However, Reberg (1982) has shown that a stimulus that has been experienced in only a few excitatory acquisition trials, or to which excitation has been extinguished and which has no obvious suppressive 
effect when presented alone, does show excitatory tendencies when presented in compound with a second excitatory stimulus. That is, when a mildly excitatory stimulus (CS2) that has no suppressive effect by itself is compounded with a known excitor (CS1), the excitatory tendencies summate to produce greater suppression of responding than is apparent to either stimulus alone. Thus, comparisons involving stimulus compounds, such as those described in the preceding paragraph, may be more revealing than a search for suppression to $X$ alone.

An alternative to the interpretation that $X$ lost its inhibitory power because of chance X-US pairings in the truly random control is an interpretation based on trial spacing. Trials were much more numerous during truly random training than during discrimination training. There is evidence in the autoshaping situation, for example (Jenkins \& Lambos, 1983), that excitatory performance (pecking a lighted key), even though strongly established, can be significantly weakened by adding more USs to the session. Furthermore, it doesn't matter whether these added USs are presented unsignaled or signaled by a second CS with which they were previously paired; the effect of the extra USs is still to weaken excitatory performance to the first CS. Although we know of no suggestion in the literature that increasing trial density weakens inhibitory performance in the same way, perhaps that possibility should be considered. If so, the evidence does not seem to favor it. For example, Rescorla (1969) held the number of CSs constant across groups and manipulated trial density by varying the number of USs given in $C S$ absence. He found that the CS's inhibitory power increased, rather than decreased, with increasing trial density. In a similar experiment, Witcher and Ayres (1980) held the number of CSs constant and held the density of USs in CS absence constant. They manipulated trial density by varying the number of USs allowed to occur in CS presence. Under these conditions, inhibition did weaken, apparently giving way to mild excitation, as the probability of a US in CS presence went from zero to a value approximating the probability of a US in CS absence (Witcher \& Ayres, 1980, Experiment 2). Thus, it appears that increasing trial density per se does not weaken inhibition unless it involves increasing the likelihood that the inhibitory CS will be paired with the US. Consistent with this statement is our present finding that increasing trial density did not reduce the inhibitory power of stimulus $Y$, which was not chance-paired with shock, but did reduce the inhibitory power of stimulus $X$, which was chance-paired with shock.

\section{GENERAL DISCUSSION}

Despite the features of our CS-alone extinction procedure, which we thought might enhance the ability of nonreinforced CSs to weaken conditioned inhibition, that procedure, in Experiment 1, was apparently with- out effect. Thus, the results of that experiment (see also Rescorla, 1982) support those of Zimmer-Hart and Rescorla (1974).

The results of Experiment 2 likewise, when taken together with those of Keller et al. (1977), support Rescorla's (1967) suggestion that the truly random control procedure might be an appropriate procedure for extinguishing both conditioned excitation and conditioned inhibition. The available data, however (Ayres \& DeCosta, 1971; Keller et al., 1977; present Experiment 2), suggest that truly random training extinguishes conditioned inhibition more rapidly than it does conditioned excitation; but this conclusion is only tentative, since the studies of excitation and those of inhibition were not performed under comparable conditions.

One theoretical mechanism through which truly random training might extinguish conditioned excitation has been discussed in some detail elsewhere (Keller et al., 1977); in the present report, we have suggested that the truly random control procedure weakens conditioned inhibition because it, like the procedure found by Zimmer-Hart and Rescorla (1974) to weaken conditioned inhibition, involves pairings of the inhibitory CS with the US.

\section{REFERENCES}

Ayres, J. J. B., Benedict, J. O., \& Witcher, E. S. (1975). Systematic manipulation of individual events in a truly random control in rats. Journal of Comparative and Physiological Psychology, 88, 97-103.

Ayres, J. J. B., \& DeCosta, M. J. (1971). The truly random control as an extinction procedure. Psychonomic Science, 24, 31-33.

Benedict, J. O., \& AYRes, J. J. B. (1972). Factors affecting conditioning of the truly random control procedure in the rat. Journal of Comparative and Physiological Psychology, 78, 323-330.

Jenkins, H. M., \& Lambos, W. A. (1983). Tests of two explanations of response elimination by noncontingent reinforcement. Animal Learning \& Behavior, 11, 302-308.

Kellen, R. J., Ayres, J. J. B., \& Mahoney, W. J. (1977). Brief versus extended exposure to truly random control procedures. Journal of Experimental Psychology: Animal Behavior Processes, 3, 53-65.

KREMER, E. F. (1971). Truly random and traditional control procedures in CER conditioning in the rat. Journal of Comparative and Physiological Psychology, 76, 441-448.

KREMER, E. F. (1974). The truly random control procedure: Conditioning to the static cues. Journal of Comparative and Physiological Psychology, 86, 700-707.

KREMer, E. F., \& Kamin, L. J. (1971). The truly random control procedure: Associative or nonassociative effects in rats. Journal of Comparative and Physiological Psychology, 74, 203-210.

QuinseY, V. L. (1971). Conditioned suppression with no CS-US contingency in the rat. Canadian Journal of Psychology, 25, 69-82.

REBERG, D. (1972). Compound tests for excitation in early acquisition and after prolonged extinction of conditioned suppression. Learning and Motivation, 3, 246-258.

Rescorla, R. A. (1967). Pavlovian conditioning and its proper control procedures. Psychological Review, 74, 71-80. 
Resconta, R. A. (1969). Conditioned inhibition of fear resulting from negative CS-US contingencies. Journal of Comparative and Physiological Psychology, 67, 504-509.

Rescorla, R. A. (1982). Some consequences of associations between the excitor and the inhibitor in a conditioned inhibition paradigm. Journal of Experimental Psychology: Animal Behavior Processes, 8, 288-298.

Rescorla, R. A., \& Wagner, A. R. (1972). A theory of Pavlovian conditioning: Variations in the effectiveness of reinforcement and nonreinforcement. In A. H. Black \& W. F. Prokasy (Eds.), Classical conditioning: $I I$. Current research and theory. New York: Appleton-Century-Crofts.

Witcher, E. S., \& AYres, J. J. B. (1975). Effect of removing background white noise during CS presentation on conditioning in the truly random control procedure. Bulletin of the Psychonomic Society, 6, 25-27.

Witche R, E. S., \& AYres, J. J. B. (1980). Systematic manipulation of CS-US pairings in negative CS-US correlation procedures in rats. Animal Learning \& Behavior, 8, 67-74.

Zimmer-Hart, C. L., \& RescorloA, R. A. (1974). Extinction of Pavlovian conditioned inhibition. Journal of Comparative and Physiological Psychology, 86, 837-845.

\section{NOTES}

1. In terms of learning mechanisms, an interdependence between A's excitation and X's inhibition could arise from principles of stimulus control: During inhibition training, the stimuli present when $\mathrm{X}$ acquires inhibitory control include $\mathrm{A}$, $X$, the $\mathbf{A X}$ configure, emotional responses and stimulus-specific conditioned and unconditioned overt behaviors controlled by $A$ and by the $A X$ configure. During the $X$-alone extinction phase, most of these stimuli by definition are missing, and so the entire complex of stimuli controlling inhibition cannot undergo extinction. If the test for inhibition were now to take the form A+ AX-, many of the previously described elements controlling inhibition (and protected from extinction) would be restored. The inhibitory power of $X$ would appear strong again, and the $X$-alone extinction procedure would appear to have failed. By presenting not only $\mathrm{X}$-alone trials but also $\mathrm{A}$-alone and $\mathrm{AX}$-alone trials during the extinction phase, we hoped to extinguish a larger portion of the stimulus complex controlling inhibition. By using a B+ BX-test, we hoped to avoid reintroducing some of those elements that had been present when inhibition was learned. Even if some of the test cues (e.g., BX) should "remind" the subject of stimulus $A$, the emotional behaviors and stimulusspecific unconditioned and conditioned overt behaviors once controlled by $\mathrm{A}$ and by the $\mathrm{AX}$ configure would be unlikely to occur in the test because the previous A-alone and AX-alone trials would have extinguished these behaviors. Once again, we would minimize the restoration of stimulus elements present when inhibition was learned, elements presumed to be in control of that inhibition.

2. All $\mathrm{p}$ values are two-tailed.

3. If we ignore the $A+$ trials, the $P(U S \mid X)=.083$ and the $\mathrm{P}(\mathrm{US} \mid \overline{\mathrm{X}})=.083 ;$ the procedure established a random relationship between $X$ and the US. If we include the two At trials, the $\mathrm{P}(\mathrm{US} ; \mathrm{X})=.083$ and the $\mathrm{P}(\mathrm{US} \mid \overline{\mathrm{X}})=.104$; the procedure involved a slightly negative contingency between $X$ and the US.

4. Data from one rat were lost through equipment failure; hence, the reduction in degrees of freedom from 6 to 5 .

(Manuscript received October 7, 1983; revision accepted for publication March 15, 1984.) 